\title{
O ACESSO À EDUCAÇÃO AOS IMIGRANTES HAITIANOS EM UMA ESCOLA PÚBLICA DE ARROIO DO MEIO
}

\author{
Alice Krämer Iorra Schmidt ${ }^{1}$ \\ Marta Luisa Piccinini ${ }^{2}$ \\ Márcia Solange Volkmer ${ }^{3}$
}

\begin{abstract}
Resumo: O direito à educação está consagrado na Constituição Federal de 1988, em seu artigo 6º como um direito social, exigindo-se dos Poderes Públicos prestaçóes positivas para sua implementaçáo. $\mathrm{O}$ acesso à educação deve ser garantido a todos os residentes no país, sejam eles brasileiros, ou estrangeiros. Analisando a situação dos estrangeiros, que historicamente receberam atenção por se constituírem como mão-de-obra para o Brasil, o presente artigo aborda a questão das imigraçóes contemporâneas, que estão a trazer novos desafios para a organização da sociedade em diversas áreas, a exemplo da saúde e moradia, e também na prestação da educação por parte do Estado. As cidades do Vale do Taquari, nos últimos anos, têm recebido um contingente expressivo de imigrantes, atraídos pelas ofertas de emprego e vínculos com imigrantes já estabelecidos - o que leva estes Municípios a criarem mecanismos para dar maior efetividade ao direito fundamental à educação destes recémchegados. $\mathrm{O}$ trabalho analisa a inserção dos imigrantes haitianos no Vale do Taquari, precisamente na cidade de Arroio do Meio/RS, e os desafios encontrados no acesso à educaçáo na localidade. Para tanto, faz-se uma pesquisa de cunho eminentemente investigativo, a partir de um estudo de caso em uma escola pública no município de Arroio do Meio. Realizaram-se levantamentos e entrevistas com as pessoas envolvidas nesse complexo processo de acolhimento e inserção na comunidade escolar. $\mathrm{O}$ trabalho sugere que, na localidade, o direito humano à educaçáo está sendo garantido, em que pese as dificuldades de adaptação encontradas inicialmente pelos imigrantes e pelos seus filhos em idade escolar.
\end{abstract}

Palavras-chave: Imigraçóes. Direito. Educação. Direitos Humanos.

1 Mestre em Direito Processual Civil pela Universidade de Coimbra-Portugal, com revalidação pela Universidade Federal do Espírito Santo. Especialista em Direito Civil e Processual Civil pela Faculdade IDC. Graduação em Ciências Jurídicas e Sociais. Professora assistente do Centro Universitário UNIVATES. E-mail: alice.iorra@univates.br

2 Mestre em Direito pela Universidade de Santa Cruz do Sul. Especialização em Direito Imobiliário. Graduação em Direito. Professora assistente do Centro Universitário UNIVATES. E-mail: martap@univates.br

3 Doutora em História pela Universidade Federal do Rio Grande do Sul. Professora do Centro Universitário UNIVATES. E-mail: marciavolkmer@gmail.com 


\begin{abstract}
The right to education is contained in the Brazilian Federal Constitution of 1988, in its article 6 , as a social right, requiring the Public Powers positive benefits for its implementation. Access to education must be guaranteed to all residents of the country, whether Brazilian or foreign. Analyzing the situation of foreigners, who have historically received attention as a labor force for Brazil, this article addresses the issue of contemporary immigration, which is bringing new challenges for the organization of society in several areas, for example health and housing, and also in the provision of education by the State. The cities of the Vale do Taquari in recent years have received a significant number of immigrants, attracted by job offers and links with established immigrants - which leads these municipalities to create mechanisms to give greater effectiveness to the fundamental right to education of these newly-combed. The paper analyzes the insertion of Haitian immigrants in Vale do Taquari, precisely in the city of Arroio do Meio / RS, and the challenges encountered in access to education in the locality. To do so, a investigative research is done, based on a case study in a public school in the municipality of Arroio do Meio. There were a data collect and interviews with the people involved in this complex process of reception and insertion in the school community. The paper suggests that in the locality the human right to education is being guaranteed, despite the difficulties of adaptation initially encountered by immigrants and their schoolchildren.
\end{abstract}

Keywords: Immigration. Law. Education. Human rights.

\title{
INTRODUÇÁO
}

A sociedade contemporânea é caracterizada pela complexidade, uma vez que se vivencia uma grande contradição: diminuição das distâncias e aumento das diferenças e dos meios de exclusão e controle. Vial (2004) afirma que não existe sociedade sem comunicação e esta por sua vez significa informação, compreensão e ato de comunicar, dando sentido à vida em sociedade.

Ao mesmo tempo em que as formas de comunicação e informação, essenciais à vida em sociedade, facilitam o fluxo de dados e diminuem algumas distâncias, principalmente as existentes entre alguns setores da sociedade, ela afasta sobremaneira as pessoas, criando barreiras, na maioria das vezes intransponíveis. Temos uma sociedade que inclui todos somente porque também é capaz, ao mesmo tempo, de excluir os "ditos" incluídos. Logo, a diferença entre inclusão e exclusão se refere ao modo pelo qual uma sociedade consente aos indivíduos serem pessoas humanas (VIAL, 2004).

Vive-se um momento de extrema valorização dos Direitos Humanos como forma de responder às mais graves necessidades da humanidade e, em contrapartida, também se assiste a inefetividade desses Direitos em algumas situações. Ao analisar os movimentos migratórios na contemporaneidade esse paradoxo fica evidente.

A chegada de imigrantes haitianos ao Brasil intensifica-se a partir de 2010, quando as consequências de um terremoto "testemunham a extrema vulnerabilidade de uma sociedade marcada pela insegurança das condições de vida de sua população" (AUDEBERT, 2012). Para os haitianos a migração constituise como elemento formador da própria sociedade e "o cataclismo agiu como um espelho e um amplificador das razões estruturais que puseram os haitianos a deixar o seu país há várias gerações" (AUDEBERT, 2012, p.11). A missão de paz 
brasileira em território haitiano e a concessão do visto humanitário foram fatores que favoreceram as correntes imigratórias de haitianos ao Brasil.

Recebidos primeiramente nos estados do Norte do país, gradativamente, constituem-se redes - de informações, apoios e oportunidades de trabalho - que atraem os imigrantes para as diferentes regiões brasileiras. No sul do país, milhares de haitianos serão atraídos para as cidades que constituem a região central do Rio Grande do Sul, onde várias empresas contratam a sua mão-de-obra. No primeiro momento essas oportunidades de trabalho atraem um grupo de imigrantes essencialmente masculino e jovem. Aos poucos, a região passa a receber também as mulheres ou então os grupos familiares.

A inserção na sociedade local exige desse grupo o domínio da língua portuguesa, o que direciona vários imigrantes na busca pela escolarização. O mesmo acontece pela necessidade de validar estudos realizados no país de origem ou então de realizarem algum curso técnico. Os filhos dos imigrantes, da mesma forma, precisam ser inseridos no sistema escolar dos municípios, o que gera um processo que nos permite analisar a efetividade dos direitos assegurados aos imigrantes no Brasil.

\section{MIGRAÇÓES INTERNACIONAIS, CIDADANIA E DIREITOS}

Quando condições desumanas de vida, crises ambientais, fome, conflitos de toda ordem, discriminação de toda e qualquer natureza, deslocam milhares de pessoas em busca de um lugar melhor para viver ou para tentar escapar da morte é que muitos tentam valer-se da garantia dada pelo direito internacional dos direitos humanos, que assegura a toda pessoa o direito de abandonar o país em que se encontra, do mesmo modo que lhe é garantido o direito de regressar ao seu país (KÖCHE, 2015, p.26).

Köche (2015, p. 26) afirma que:

Em termos de direito internacional, não é possível assegurar o direito correspondente de entrar no território de um determinado Estado. Isso significa dizer que posso abandonar qualquer país, sem que isso signifique que posso ingressar em qualquer país, devendo obter autorização deste para poder entrar e permanecer em seu território. Universalmente falando, não nos é garantido o direito à livre circulação internacional.

Porém, a ninguém é dado o direito de ignorar a proteção da legislação constitucional e infraconstitucional que é conferida a todo migrante que escolhe o Brasil para viver. $\mathrm{O}$ caput do artigo $5^{\circ}$ da Constituição Federal diz que os direitos fundamentais são assegurados aos "brasileiros e estrangeiros residentes no País" (BRASIL, 1988, texto digital). Assim, orientando-se pelo princípio da dignidade da pessoa humana, insculpido no artigo $1^{\circ}$, III, e pelos direitos fundamentais contidos no referido dispositivo constitucional, conjuntamente com os princípios da isonomia e universalidade, pretendeu o legislador constituinte atribuir direitos fundamentais a todos os seres humanos, independentemente de nacionalidade. Com 
base neste arcabouço normativo, é possível concluir-se que toda e qualquer pessoa, seja brasileira ou estrangeira residente no país, é titular de direitos fundamentais.

No entanto, na trajetória de constituição da cidadania no Brasil, por um longo período, a situação do estrangeiro foi de exclusão. Essas questões ganham maior destaque a partir do século XIX, quando imigrantes de diferentes nacionalidades chegam ao país e começam a reivindicar por seus direitos. Inseridos em uma política clara de atração de mão-de-obra e ocupação do território, os imigrantes se deparam com uma realidade bastante distinta daquela preconizada na legislação.

A segunda metade do século XIX é marcada no Brasil por planos e ações estatais que pretendiam consolidar um projeto de nação. Questões centrais como a intervenção do Estado na sociedade, a sua matriz econômica e a constituição de uma identidade nacional pautaram as discussões do período. Um projeto de nação, orientado para o progresso, estava nas mentes das elites latino-americanas. Para tanto, um novo sistema político e econômico deveria ser pensado e instituído.

Nesse processo, a questão do progresso econômico recorrentemente foi associada à questão populacional e ao desenvolvimento da agricultura, para as quais a imigração europeia teria papel central. Assim, coube à elite intelectual e/ ou política estabelecer as diretrizes e os incentivos para tal corrente que acabou por atrair milhares de europeus às terras ditas "desertas" na América do Sul. Para esses "pensadores da nação", a mudança econômica estava necessariamente atrelada à mudança política e social, fatores dependentes da ocupação e legitimação do território.

Del siglo XVI al XVIII, la defensa y manutención de los fondos territoriales del continente americano constituyeron un objetivo muy claro de las metrópolis ibéricas. En el siglo XIX, cuando las poblaciones de las antiguas regiones coloniales iniciaron el proceso que culminaría con la organización de nuevos Estados nacionales, adoptaron la perspectiva de los colonizadores observando los "fondos territoriales" como espacios a ser ocupados, defendidos y explorados. El "senhoriato" rural (los grandes señores de tierras) brasilero, por ejemplo, mirándose como heredero de la metrópoli, asimiló el pasado colonial enfatizando la continuidad aun donde ella no existía como aparece con nitidez en uno de los mitos fundadores de la nación, que considera la integridad territorial del imperio una dádiva de la metrópoli. Esa camada de la población, por no reconocerse en la masa de esclavos y mestizos, que constituían la mayoría de la población, identifica el país con el territorio (supuestamente heredado) y considera la tarea fundamental del Estado la defensa de la soberanía sobre los fondos territoriales y su objetivo primordial la ocupación del territorio. (SILVA, 2004, p.07).

Nesse sentido "en el cuadro de la formación nacional hay un territorio a ocupar y un Estado en construcción, pero la población disponible no se ajusta a los modelos identitarios vigentes en los centros hegemónicos" (SILVA, 2004, p. 07). Diante da inadequação da população mestiça e escrava para constituir as bases da nação, as elites construiriam uma imagem do ideal de imigrante e do ideal de imigração. Nessa construção, seria o trabalho do imigrante europeu que possibilitaria a ocupação e exploração agrícola de áreas ainda não aproveitadas 
economicamente, ou então seria a mão de obra que em breve substituiria aquela ocupada pela escravidão. Ao mesmo tempo, seriam esses imigrantes a força propulsora do progresso e da civilização, uma vez que trariam os hábitos de trabalho e civilidade europeus.

Em relação à definição do que seja um "imigrante", Fernando Devoto salienta que a noção não é direta e foi mudando ao longo do tempo. De acordo com este autor, nas sociedades antigas, certamente era muito difícil estabelecer quem era um estrangeiro, afinal, o pertencimento legal de uma pessoa era impreciso, e poderia mudar depois de uma guerra. Neste período, "el sentido de pertenencia, definirse en relación con 'otros', no iba, en la mayoria de los casos, más allá de un ámbito local o regional” (DEVOTO, 2004, p. 21).

Será o Estado moderno "el que se empeña en clasificar, en definir, a la vez a los ciudadanos que gozan de ciertos derechos y a los extranjeros que no pueden beneficiarse de tales" (DEVOTO, 2004, p. 21). Nesse sentido, o autor salienta a importante diferença entre um imigrante e um estrangeiro, categorias que não podem ser associadas indistintamente no século XIX. Para aqueles que se deslocam de um lugar para outro podemos fazer uso de vários termos: viajantes, estrangeiros, imigrantes, exilados. No entanto, o "imigrante" pretendido e referenciado nas políticas públicas no século XIX é uma categoria dotada de sentido muito específico.

No século XIX, na perspectiva das elites sul-americanas, imigrante era aquele indivíduo europeu que viria para "povoar o deserto" e "cultivar as terras". O imigrante nesse contexto era sinônimo de trabalho e civilidade, apesar da pobreza que o caracterizava na origem. Nesse período, na Argentina, nem todo estrangeiro era tido como um imigrante - os comerciantes, engenheiros, médicos e políticos europeus que viviam no país em nenhum momento eram considerados imigrantes pela elite. Eram a bagagem cultural, os hábitos de consumo, o prestígio do grupo de origem e os meios em que circulavam que definiam a diferença entre as duas categorias. Será na segunda metade do século XIX que a noção de imigrante adquire suas formulações mais sistemáticas e conceitualmente mais abrangentes (DEVOTO, 2004).

Ellas se plasman en el carácter civilizatório atribuído al rol del inmigrante en la sociedad argentina, en especial en la obra de Juan Bautista Alberdi, pero también en la Constitución de 1853 y en la ley de inmigración y colonización de 1876. Esta última daba una definición de inmigrante que servía para delimitar quiénes tenían derecho a los benefícios que ofrecía el Estado argentino. En sus términos, inmigrante era el europeo. (DEVOTO, 2004, p.30).

A definição jurídica na Argentina, de acordo com a Lei de Imigração e Colonização, deixava explícito que imigrante era aquele estrangeiro que viajava em barcos oriundos de portos europeus, com o objetivo de estabelecer-se no novo país. Para serem enquadrados nesta categoria, deveriam ter viajado em segunda ou terceira classe, ter menos de 60 anos e estar livres de qualquer defeito físico ou doença. A lei deixava claro tratar-se de mão de obra para o país, empregada especialmente nas tarefas manuais e, sobremaneira, para cultivar o campo. 
No Brasil, a preferência era por imigrantes/colonos de "idades de 10 a 50 anos, acompanhados dos certificados dos cônsules brasileiros, de que são pessoas de bons costumes, e que pelas suas ocupações, ou meios de vida sejam próprios para viver do trabalho de suas mãos". Enfatizava-se que "para ser colono é indispensável ser moço, sadio, e casado com mulher moça." ${ }^{4}$ Em ambos os países, portanto, a definição e qualificação de imigrante está associada àquela de trabalhador europeu.

Da mesma forma, atrelava-se a presença dos imigrantes europeus com o desenvolvimento da agricultura e consequente progresso econômico do país. No Rio Grande do Sul, em 1850, a colonização era um assunto "de alto interesse para a Província". De acordo com as autoridades estaduais "a colonização conduz consigo para o país que ela demanda população, variados conhecimentos da agricultura, e diferentes processos das artes úteis; ela dá incremento à produção e ao consumo: acumulando sucessivamente os capitais e desenvolvendo o trabalho, cria e distribui a riqueza." 5

No Brasil, o incentivo à vinda dos imigrantes aumenta com a promulgação da Lei de Terras em 1850, quando o Estado passa a ter o controle sobre as terras devolutas e sobre a sua venda, bem como em relação a outras leis relacionadas ao patrocínio da imigração. Uma importante participação do Estado na promoção da imigração era a política de criação de colônias, públicas ou particulares. Nesses casos, o Estado patrocinava os custos da viagem e também a concessão de lotes de terras. No Brasil, da mesma forma, a partir de 1850, caberá às províncias um maior envolvimento nas questões que regulavam e incentivavam a imigração. No Rio Grande do Sul, a primeira lei sobre colonização é de 1851, referente à medição e demarcação das terras para os colonos que chegavam.

Iniciava-se, portanto, uma intervenção ativa do Estado na promoção da imigração europeia. A vinda desses imigrantes, no entanto, já acontecia há muito tempo, e as redes sociais estabelecidas entre os grupos eram fortes alicerces para a vinda de outros indivíduos. O fluxo, portanto, já existia. O que se fazia nos círculos intelectuais eram a construção e legitimação de uma "retórica pró-migratória", como a intitula Devoto. Para este autor, "essas retóricas e essas iniciativas não deixaram de operar e criaram um clima muito favorável para a acolhida dos imigrantes e a partir daí também para seu êxito social.” (DEVOTO, 2004, p. 229).

4 Regulamento de Imigração de 1848. Arquivo Histórico do Rio Grande do Sul - Aditamento feito ao relatório, que perante a Assembleia Provincial do Rio Grande de São Pedro do Sul, dirigiu o exmo. vice-presidente da província em sessão de 4 de março de 1848, pelo ilmo. e exmo. sr. presidente da província e comandante do exército em guarnição, Francisco José de Souza Soares de Andréa, para ser presente a mesma Assembleia. Porto Alegre: Typ. do Commercio, 1848, p. 19.

5 Arquivo Histórico do Rio Grande do Sul - Relatório do Presidente da Província de São Pedro do Rio Grande do Sul, o conselheiro José Antonio Pimenta Bueno, na abertura da Assembleia Legislativa Provincial no. $1^{\circ}$ de outubro de 1850; acompanhado do orçamento da receita e despesa para o ano de 1851. Porto Alegre: Typ. de F. Pomatelli, 1850, p.23. 
Essa imagem e grande expectativa e otimismo estarão relacionadas ao processo de atração de imigrantes para a América do Sul até a década de 1880. Nesse período, quando milhões de imigrantes desembarcam nos portos platinos é que passa a vincular-se uma ideia socialmente mais restritiva desses indivíduos e de sua inserção no novo país. Ao findar do século XIX, a imigração começava a tornar-se um problema para a elite, que precisava, a todo custo, manter a sua posição social, impedindo a ascensão dos recém-chegados. Em relação aos imigrantes vindos de regiões não europeias, a resistência seria ainda maior.

Nesse novo contexto, leis impositivas e restritivas deixam bastante evidente que há um conjunto da população que vive no Brasil que não pode partilhar dos mesmos direitos. Inaugura-se, em 1889, uma República da exclusão e do preconceito. Com um discurso que tenta encobrir as reais condições de vida da maioria da população, preconizando ações saneadoras e moralizadoras, a população imigrante será vista com desconfiança e preconceito. No entanto, tenta-se manter aquela imagem do século anterior, quando o Estado regulava as fronteiras pensando unicamente em atrair mão-de-obra branca, constituindo um discurso que passa a naturalizar a desigualdade no país.

Esse processo de naturalização da desigualdade desemboca nos dias de hoje, evidenciando que, por meio do Direito, a capacidade transformadora sugerida pela Constituição ainda está longe de atingir a sua plenitude no que diz respeito a cura da ferida social pela transformação (do status quo) da realidade periférica brasileira, haja visto que os juristas ainda seguem atrelados ao formalismo normativista, operando, por consequência, o recalque das potencialidades transformadoras do direito e a efetivação de uma hermenêutica emancipatória, assegurando, por conseguinte, o distanciamento do saber jurídico da realidade social. Nesse diapasão, os operadores jurídicos acabam se transformando em reprodutores de fórmulas antigas e mantenedores de um sistema social que avilta as condições de vida da grande massa oprimida e o direito passa a ser a ferramenta deste mecanismo. (MOREIRA; PAULA, 2015, p.25).

$\mathrm{Na}$ atualidade, numa interpretação mais extensiva, dada por Ingo Wolfgang Sarlet (2009a), em homenagem ao princípio da dignidade da pessoa humana, isonomia e universalidade, são compreendidos como estrangeiros residentes todos os que, não sendo brasileiros natos ou naturalizados, se encontram, pelo menos temporariamente, no País, guardando, portanto, algum vínculo de certa duração. Ou seja, pode-se afirmar, baseado no princípio da universalidade, que todos os direitos diretamente fundados na dignidade da pessoa humana são extensivos aos estrangeiros, residentes ou não residentes no País.

Sarlet (2009a) ainda salienta ser de tal forma indissociável a relação entre a dignidade da pessoa humana e os direitos fundamentais que mesmo nas ordens normativas nas quais a dignidade ainda não mereceu referência expressa, não se poderá, apenas a partir deste dado - concluir que não se faça presente, na condição de valor informador de toda a ordem jurídica, desde que nesta ordem jurídica estejam reconhecidos e assegurados os direitos fundamentais inerentes à pessoa humana. 
Porém, esses direitos fundamentais, assegurados aos nacionais e aos estrangeiros por si só não têm efetividade e necessitam de Políticas Públicas que os implementem. Nesse sentido é o direito à educação, elevado ao patamar de Direito Fundamental da pessoa humana, que está assegurado no plano interno e internacional, como se pode ver a seguir.

\section{EDUCAÇÃO E DIREITOS HUMANOS}

Inicialmente a Declaração dos Direitos do Homem e do Cidadão (1793), fruto do contexto da Revolução Francesa, no séc. XVIII, afirmava em seu artigo XXII:

Artigo XXII - A instrução é a necessidade de todos. A sociedade deve favorecer com todo o seu poder o progresso da inteligência pública e colocar a instrução ao alcance de todos os cidadãos (DECLARAÇÃO, 1793, texto digital).

Após, já no século XX, a Declaração Universal dos Direitos do Homem (1948), em seu artigo XXVI, reafirma:

1.Todo ser humano tem direito à instrução. A instrução será gratuita, pelo menos nos graus elementares e fundamentais. A instrução elementar será obrigatória. A instrução técnico-profissional será acessível a todos, bem como a instrução superior, esta baseada no mérito (ORGANIZAÇÃO DAS NAÇÕES UNIDAS, 1948, texto digital).

A partir desses dispositivos, a educação passa a ser considerada o componente fundamental dos direitos humanos, tanto o é que foi tema de debate na Conferência Mundial sobre Direitos Humanos, no ano de 1993, em Viena.

No documento, Declaração de Viena, a educação está elevada a pressuposto fundamental para o entendimento dos demais direitos humanos e deverá incluir a paz, a democracia, o desenvolvimento e a justiça social, conforme definidos nos instrumentos internacionais e regionais de Direitos Humanos.

Para Benevides (texto digital), a educação em Direitos Humanos é essencialmente a formação de uma cultura de respeito à dignidade humana através da promoção e da vivência dos valores da liberdade, da justiça, da igualdade, da solidariedade, da cooperação, da tolerância e da paz.

Nesse sentido, pode-se afirmar que o direito à educação também está reconhecido juridicamente no Pacto Internacional dos Direitos Econômicos, Sociais e Culturais (1966), ratificado pelo Brasil em 1992, através do Decreto-Lei 591. Em seu art. 13 é afirmado:

Artigo 13. [...]

\$1. Os Estados-partes no presente Pacto reconhecem o direito de toda pessoa à educação. Concordam em que a educação deverá visar ao pleno desenvolvimento da personalidade humana e do sentido de sua dignidade e a fortalecer o respeito pelos direitos humanos e liberdades fundamentais. Concordam ainda que a educação deverá capacitar todas as pessoas a 
participar efetivamente de uma sociedade livre, favorecer a compreensão, a tolerância e a amizade entre todas as nações e entre todos os grupos raciais, étnicos ou religiosos e promover as atividades das Nações Unidas em prol da manutenção da paz

§2. Os Estados-partes no presente Pacto reconhecem que, com o objetivo de assegurar o pleno exercício desse direito:

1. A educação primária deverá ser obrigatória e acessível gratuitamente a todos.

2. A educação secundária em suas diferentes formas, inclusive a educação secundária técnica e profissional, deverá ser generalizada e tornar-se acessível a todos, por todos os meios apropriados e, principalmente, pela implementação progressiva do ensino gratuito.

3. A educação de nível superior deverá igualmente tornar-se acessível a todos, com base na capacidade de cada um, por todos os meios apropriados e, principalmente, pela implementação progressiva do ensino gratuito.

4. Dever-se-á fomentar e intensificar, na medida do possível, a educação de base para aquelas pessoas não receberam educação primária ou não concluíram o ciclo completo de educação primária.

5. Será preciso prosseguir ativamente o desenvolvimento de uma rede escolar em todos os níveis de ensino, implementar-se um sistema adequado de bolsas de estudo e melhorar continuamente as condições materiais do corpo docente.

6. Os Estados-partes no presente Pacto comprometem-se a respeitar a liberdade dos pais e, quando for o caso, dos tutores legais, de escolher para seus filhos escolas distintas daquelas criadas pelas autoridades públicas, sempre que atendam aos padrões mínimos de ensino prescritos ou aprovados pelo Estado, e de fazer com que seus filhos venham a receber educação religiosa ou moral que esteja de acordo com suas próprias convicções.

7. Nenhuma das disposições do presente artigo poderá ser interpretada no sentido de restringir a liberdade de indivíduos e de entidades de criar e dirigir instituições de ensino, desde que respeitados os princípios enunciados no parágrafo $1^{\circ}$ do presente artigo e que essas instituições observem os padrões mínimos prescritos pelo Estado (BRASIL, 1992, texto digital).

E por fim, a Constituição Federal de 1988 (BRASIL, 1988, texto digital), no art. 205, assevera que:

Art. 205 - a educação, direito de todos e dever do Estado e da família, será promovida e incentivada com a colaboração da sociedade, visando ao pleno desenvolvimento da pessoa, seu preparo para o exercício da cidadania e sua qualificação para o trabalho.

A titularidade do direito fundamental à educação é extensível aos brasileiros e estrangeiros e tal garantia importa sobremaneira às imigrações contemporâneas, que estão a trazer novos desafios para a organização da sociedade.

Teixeira (2015, p. 23), ao referenciar Taylor, afirma que, mesmo em sociedades multiculturais como o Brasil deve haver uma normativa clara sobre o reconhecimento dos direitos das minorias e que atualmente, a grande dificuldade que os fluxos migratórios apresentam aos países de destino está concentrada em 
criar estruturas políticas e, por consequência, normativas jurídicas em condições de possibilitar a inclusão do migrante e de toda a tradição cultural que ele traz consigo.

Gorczevski (2005) entende que o elemento de fundamental importância para a cidadania plena é a educação. E o que se busca é o desenvolvimento integral do homem, o respeito aos direitos humanos e às liberdades fundamentais, a compreensão, a tolerância e a amizade entre os grupos étnicos e religiosos e entre as nações, acreditando ser esta a base para a cidadania.

No contexto das migrações contemporâneas, o debate sobre direitos assegurados aos recém-chegados mostra-se premente, incluindo-se aí o direito à educação de adultos e crianças provenientes de países estrangeiros.

Nesse sentido, as cidades do Vale do Taquari, no Estado do Rio Grande do Sul, nos últimos anos, têm recebido um contingente expressivo de imigrantes, atraídos pelas ofertas de emprego, principalmente na indústria e construção civil, e melhor qualidade de vida - o que obriga estes Municípios a criarem mecanismos para implementação de direitos básicos a estes indivíduos.

\section{A INSERÇÃO DE ALUNOS HAITIANOS EM UMA ESCOLA PÚBLICA DE ARROIO DO MEIO}

A partir de um estudo de caso em uma escola pública municipal da cidade de Arroio do Meio, pretende-se analisar os desafios encontrados pelos imigrantes no acesso à educação na localidade. Da mesma forma, entender os contextos e processos educativos que envolvem os profissionais que atuam diretamente com os alunos haitianos dos anos iniciais e finais do ensino fundamental.

Foram realizadas entrevistas ${ }^{6}$ in loco com duas pessoas da equipe diretiva da escola e, posteriormente, com um professor que leciona na instituição de ensino. Justamente por isso, se trata de análise da percepção destes educadores a respeito do processo de inserção dos imigrantes na escola, não se descartando a possibilidade de as percepções individuais destes não condizerem com perfeição à realidade dos demais espaços educativos da região. De todo modo, válidas são as

6 As pesquisadoras realizaram as seguintes perguntas aos entrevistados:

a) Quantos alunos a escola possui?

b) Quantos alunos haitianos a escola possui?

c) Por qual motivo os alunos escolheram esta escola para estudar na cidade de Arroio do Meio?

d) Desde quando a escola vem recebendo alunos estrangeiros (haitianos)?

e) Houve preparo prévio para qualificar o corpo docente para receber os alunos imigrantes?

f) Quais as principais dificuldades na inserção dos alunos na escola?

g) Como os alunos brasileiros se comportam em relação alunos imigrantes?

h) Qual a faixa etária dos alunos imigrantes?

i) A escola tem contato com a família dos alunos imigrantes?

j) A escola realizou alguma atividade de inclusão?

k) As famílias dos imigrantes participam das atividades promovidas pela escola?

l) É permitido aos alunos imigrantes, na realização das avaliações, a utilização de ferramentas que facilitem a compreensão da língua portuguesa? 
constatações destes sujeitos, haja vista a proximidade que possuem com a realidade dos imigrantes na escola.

O educandário analisado conta, atualmente, com 372 alunos, dos quais 6 são haitianos de idades que variam entre 6 a 17 anos - e a chegada destes alunos para a escola, que fica num bairro industrial da cidade, representou uma mudança significativa na dinâmica de ensino-aprendizagem. O número expressivo de indústrias no bairro em que está localizada a escola foi o fator determinante para a escolha daquela localidade para fixação de residência pela família e matrícula dos filhos imigrantes, facilitando a logística diária de deslocamento.

O primeiro ponto a se destacar é que não existe uma política estadual ou municipal para o acolhimento dos imigrantes nas escolas. Nesse sentido, cada escola tem total autonomia para a realização dos procedimentos que julgar importantes, como o contato com a família dos alunos e a sua classificação na série que julgar conveniente.

No contexto analisado nesta pesquisa, algumas adaptações na sistemática de aula foram realizadas para permitir um melhor acolhimento dos imigrantes pela escola e superar algumas dificuldades com relação à comunicação. Num primeiro momento, a instituição buscou auxílio de uma pessoa, na comunidade, que falasse francês para permitir esse contato inicial com os pais dos alunos estrangeiros, compreender quem eram esses recém-chegados, onde estavam trabalhando no Brasil, no que trabalhavam no Haiti e traduzir eventuais documentações.

Essa dificuldade também é evidenciada por Barausse (2013, texto digital), ao dizer que uma das grandes barreiras encontradas pelos haitianos ao ingressarem no país é referente à língua, haja vista que um número expressivo destes imigrantes fala espanhol, crioulo e francês.

Na sala de aula, a comunicação foi estabelecida através do uso de computador ou aparelho celular para acessar programas de tradução, a exemplo do Google Tradutor, a fim de permitir a melhor compreensão, por alunos e professores, do francês e do crioulo haitiano, que são as línguas oficiais do Haiti.

Percebeu-se, por parte das crianças residentes no local, um forte sentimento de acolhida e solidariedade para com os estrangeiros. Não raras vezes estes profissionais depararam-se com situações em que as crianças, diante de um objeto qualquer, buscavam ensinar aos haitianos o vocábulo em língua portuguesa; organizavam os seus horários de aula, de forma colorida, para facilitar a compreensão por parte dos mesmos; passavam a limpo seus materiais para se tornar compreensível. De fato, pelo que relataram os funcionários da escola, os imigrantes foram recebidos pelos colegas de uma forma muito natural e humana, inclusive, sem qualquer preconceito ou discriminação.

Relatam os profissionais que lidam diretamente com os pais de alunos haitianos que estes valorizam a escola de forma exemplar, preocupam-se sobremaneira com o ensino e, por isso, procuram participar ativamente de 
atividades propostas e reuniões - e isso tem contribuído para a melhor adaptação destes alunos estrangeiros.

Sensível a este processo de adaptação das famílias estrangeiras à nova realidade, a escola também realizou uma campanha de arrecadação de roupas, eletrodomésticos e mobiliários, tendo sido surpreendida positivamente com o engajamento dos alunos brasileiros à causa. Foi a forma encontrada pela instituição de ensino para, de uma forma participativa, contribuir para a melhor acomodação destas pessoas na cidade, garantindo-lhes o mínimo para uma existência digna.

Ao encontro do que se constatou na entrevista, Mattos, Sarturi e Borges (2015, p.68) destacam que:

Partindo-se do pressuposto de que migrar é inerente a todos - haja visto a mobilidade ser um processo natural - e, portanto, um direito humano, deve ser assegurado, onde quer que seja, um local adequado e uma vida digna àqueles que decidem dar um novo rumo à sua vida ou são forçados a tanto. Nesse sentido é que as políticas públicas devem ser pensadas e propostas, de modo que o imigrante seja, de fato, sujeito de direitos e não fique submetido a condições desumanas - semelhantes ou, muitas vezes, piores - àquelas das quais está buscando melhoria.

Numa análise ainda preliminar da situação naquela escola, a pesquisa sugere que o direito à educação está sendo eficazmente implementado, que os problemas estão sendo contornados à medida do possível, e que isso decorre mais do esforço conjunto dos profissionais envolvidos com a família dos alunos estrangeiros do que pelo Poder Público Municipal. Isso porque a escola não recebeu qualquer treinamento ou orientação prévia por parte da municipalidade para a acolhida dos imigrantes e, por isso, a adaptação destes alunos à nova realidade deve-se sobremaneira à boa vontade daqueles que estão envolvidos neste processo.

Nesta medida, percebe-se um clamor por propostas concretas que de fato implementem medidas efetivas do discurso garantista e humanista aos imigrantes, tendo em vista que a falta de políticas públicas só se tornam permanentes quando o Estado se omite no seu dever de acolher e respeitar a dignidade do todo ser humano nos seus mais diferentes espectros.

Considerando os direitos fundamentais como expressões da dignidade humana, por via de consequência, pode-se dizer que em cada direito fundamental - como, no caso em análise, a educação - se faz presente um conteúdo, ou, pelo menos, alguma projeção, da dignidade humana (SARLET, 2009b). Assim, na exata medida em que o Estado se omite na concretização de um direito fundamental, também está ofendendo a dignidade do ser humano que se vê privado do gozo de seus direitos.

Note-se, por isso, que embora o direito à educação esteja sendo concretizado na escola, o sistema jurídico ainda é absolutamente inseguro e frágil neste aspecto. Isso leva a crer que, em outras localidades, a situação dos haitianos seja absolutamente discrepante, pois a implementação de um direito humano e fundamental, previsto pela Constituição Federal e Tratados Internacionais, depende de políticas públicas 
concretas que o implementem eficazmente e não, apenas, de boa vontade. É preciso ficar claro que cumprir dispositivos legais, nacionais e estrangeiros, não é uma faculdade que o legislador confere aos entes públicos; é um dever e, portanto, é preciso que se garanta a sua concretude no plano fático.

\section{CONSIDERAÇÓES FINAIS}

O reconhecimento do direito à educação, no plano interno e internacional, tem sido formalmente admitido pelo Brasil no decorrer de sua história. O país é signatário de tratados internacionais que garantem a todos, indistintamente, o direito humano à educação, tendo também o constituinte originário previsto este tão importante direito no âmbito da Constituição Federal de 1988.

A prática, no entanto, às vezes revela que a concretização deste direito é falha aos nacionais e estrangeiros que aqui residem, haja vista o direito à educação depender de políticas públicas que o implementem eficazmente.

No contexto das migrações contemporâneas, que estão a trazer novos desafios para muitas cidades brasileiras, elementar trazer à tona a importância da concretização fática do direito à educação àqueles que desejam ter o Brasil como novo depositário de toda a sua esperança de uma vida melhor.

As cidades do Vale do Taquari, no Rio Grande do Sul, estão dentre as escolhidas pelos imigrantes haitianos, nos últimos anos, para fixação de novas moradias e colocação no mercado de trabalho. Muitos destes imigrantes possuem filhos em idade escolar, e estas crianças e adolescentes então chegando à rede municipal de ensino. Por isso, a pesquisa tratou de entrevistar profissionais que atuam diretamente com estes pais e alunos, com o intuito de investigar se, no caso da escola municipal escolhida, o direito à educação está ou não sendo efetivamente implementado.

De fato, o que se pode perceber é que esta escola está, aos poucos, adaptando-se à nova realidade dos alunos imigrantes. Foram percebidas pelas pessoas entrevistadas dificuldades na linguagem (comunicação), na adaptação à nova realidade de clima e na estruturação de novas residências pelos imigrantes, sendo que o educandário, através de solidariedade, tratou por contorná-las de forma exemplar. Através do uso de tecnologias, a dificuldade na língua portuguesa está sendo dirimida; por meio de campanhas solidárias foram arrecadadas roupas e móveis às famílias; pelo empenho de toda a comunidade escolar todos os empecilhos estão sendo resolvidos paulatinamente.

No entanto, o que nitidamente se constata é que tais medidas decorrem muito mais do esforço coletivo e do senso de humanidade de todos os sujeitos envolvidos do que de ações dos Poderes Públicos, o que torna o sistema altamente frágil e, possivelmente, em outras localidades, a realidade seja diametralmente distinta.

A implementação do direito à educação, como se viu, é um dever do Estado e não uma faculdade. Portanto, não pode depender somente à boa-fé dos agentes, 
mas, sobretudo, da organização de programas e ações que permitam maior segurança e certeza na sua concretização.

Direitos que não se concretizam não são direitos; são apenas texto de lei sem qualquer valor prático - e é exatamente isso que se pretende combater no que toca ao direito à educação dos estrangeiros imigrantes no Brasil. Para além de uma mera previsão em textos de lei, visa-se a concretude deste direito fundamental.

\section{REFERÊNCIAS}

AUDEBERT, Cédric. La diaspora haïtienne: territoires migratoires et réseaux transnationaux. Rennes: Presses Universitaires de Rennes, 2012.

BARAUSSE, Paulo Tadeu. Sofridas histórias de migração. A vida dos haitianos no Brasil. Disponível em: < http://www.ihu.unisinos.br/entrevistas/516902-sofridashistorias-de-migracao-a-vida-dos-haitianos-no-brasil-entrevista-especial-com-paulo-tadeubarausse>. Acesso em 09 nov. 2016.

BENEVIDES, Maria Victória. Educação em Direitos Humanos: de que se trata? Disponível em: <http://www.hottopos.com/convenit6/victoria.htm>. Acesso em 27 jul 2016.

BRASIL. Decreto $\mathbf{n}^{\circ}$ 591, de 6 de julho de 1992. Atos Internacionais. Pacto Internacional sobre Direitos Econômicos, Sociais e Culturais. Promulgação. Disponível em: <http:// www.planalto.gov.br/ccivil_03/decreto/1990-1994/d0591.htm>. Acesso em 30 jul. 2016.

BRASIL. Constituição da República Federativa do Brasil de 1988. Promulgada em 5 de outubro de 1988. Disponível em: <http://www.planalto.gov.br/ccivil_03/ constituicao/constituição.htm>.

DECLARAÇÃO DOS DIREITOS DO HOMEM E DO CIDADÃO. Admitidos pela Convenção Nacional em 1793 e afixada no lugar das suas reuniões. Disponível em: <http://www.dhnet.org.br/direitos/anthist/dec1793.htm>. Acesso em 30 jul. 2016.

DEVOTO, Fernando. Historia de la Inmigración en la Argentina. 2.ed. Buenos Aires: Editorial Sudamericana, 2004.

GORCZEVSKI, Clóvis. Direitos Humanos Educação e Cidadania. Direitos sociais e políticas públicas: desafios contemporâneos. Santa Cruz do Sul: EDUNISC, 2005.

KÖCHE, Rafael. Migrações e (de)igualdade no século XXI: entre políticas públicas de redistribuição e de reconhecimento. In: MORAES, José Luís Bolzan de. (Org.). Direito dos migrantes. São Leopoldo: Ed. UNISINOS, 2015, p. 25-41.

MATTOS, Alice Lopes; SARTURI, Cristina Arruda; BORGES, Leonardo Antunes. Políticas Públicas de Acolhida a Imigrantes: Discussões e Experiências. In: REDIN, Giuliana; MINCHOLA, Luís Augusto Bittencourt (Coords). Imigrantes no Brasil: proteção dos direitos humanos e perspectivas político-jurídicas. Curitiba: Juruá, 2015. 
MOREIRA, Nelson; PAULA, Rodrigo. Lima Barreto: subcidadania, negação do Estado de Direito e Constitucionalismo Dirigente no Brasil. In: Direito e Literatura. Ijuí: Unijuí, 2015.

ORGANIZAÇÃO DAS NAÇÕES UNIDAS. Declaração universal dos direitos humanos. 10 de dezembro de 1948. Disponível em: <http://www.dudh.org.br/wpcontent/uploads/2014/12/dudh.pdf>. Acesso em 30 jul. 2016.

SARLET, Ingo Wolfgang. A eficácia dos direitos fundamentais: uma teoria dos direitos fundamentais na perspectiva constitucional. 10 ed. Porto Alegre: Livraria do Advogado Editora, 2009a.

. Dignidade da pessoa humana e direitos fundamentais na Constituição Federal de 1988. 7.ed. Porto Alegre: Livraria do Advogado Editora, 2009b.

SILVA, Ligia Osório. Las tierras públicas en la construcción del Estado: una perspectiva comparada. Anais do II Congresso Nacional de História Económica. México: Ciudad Universitaria, 2004.

VIAL, Sandra Regina Martini. et al. Sociedade contemporânea: o paradoxo da inclusão/exclusão social no contexto da Global. Direitos sociais e políticas públicas: desafios contemporâneos. Santa Cruz do Sul: EDUNISC, 2004. 